\title{
Foreign Body Emboli following Cerebrovascular Interventions: Clinical, Radiographic, and Histopathologic Features
}

\author{
M. Shapiro, M.D. Ollenschleger, C. Baccin, T. Becske, G.R. Spiegel, Y. Wang, X. Song, E. Raz, D. Zumofen, M.B. Potts, and P.K. Nelson
}

\begin{abstract}
SUMMARY: Foreign material emboli following cerebral, cardiac, and peripheral catheterizations have been reported since the mid-1990s. Catheter coatings have been frequently implicated. The most recent surge of interest in this phenomenon within the neurointerventional community is associated with procedures using flow-diversion devices for the treatment of cerebral aneurysms. Following coil-supported Pipeline embolization in 4 cases and stent-supported coiling in 1, 5 patients developed multiple subcentimeter enhancing lesions, usually with surrounding edema and variable magnetic susceptibility in the vascular territories of the treated aneurysms. Conventional angiography findings were unrevealing. Laboratory work-up showed mild CSF protein elevation with no leukocytosis. Brain biopsy in 2 cases revealed granulomatous angiitis encasing foreign material, identical in stain appearance to a polyvinylpyrrolidone catheter coating. Corticosteroid administration typically produced clinical improvement. A heterogeneous radiographic and clinical course was noted, with rise and fall in the number of enhancing lesions in 2 patients and persistence in others. The etiology may be related to widespread adoption of increasingly sophisticated catheterization techniques.
\end{abstract}

ABBREVIATIONS: PRU $=$ P2Y12 reaction units; $\mathrm{PVP}=$ polyvinylpyrrolidone

$\mathbf{F}_{\mathrm{n}}^{\circ}$ oreign material embolization into the cerebral arteries during neurointerventional procedures has emerged as 1 potential cause of periprocedural ischemic stroke and ipsilateral parenchymal hemorrhage. A histopathologic study by $\mathrm{Hu}$ et $\mathrm{al}^{1}$ described 3 patients dying from intracerebral hemorrhage shortly after embolization with the Pipeline Embolization Device (Covidien, Irvine, California). Postmortem examination showed polyvinylpyrrolidone (PVP), a hydrophilic material coating the outer surface of many catheters, ${ }^{2}$ within cerebral vessels surrounding parenchymal hematomas. Cruz et $\mathrm{al}^{3}$ described 7 patients with subacute development of nonlethal enhancing lesions in the territory of prior catheter intervention, with extensive surrounding vasogenic edema and variable susceptibility. No biopsy was reported; the authors concluded that foreign body emboli were likely responsible.

Received December 27, 2014; accepted after revision March 24, 2015.

From the Departments of Radiology (M.S., M.D.O., T.B., E.R., D.Z., M.B.P., P.K.N.), Bernard and Irene Schwartz Neurointerventional Radiology Section, Neurology (M.S., T.B.), and Neurosurgery (D.Z. M.B.P., P.K.N.), New York University Langone Medical Center, New York University School of Medicine, New York, New York Departments of Radiology (G.R.S.) and Pathology (X.S.), Hartford Hospital, Hartford, Connecticut; Department of Interventional Neuroradiology (C.B.), São Paulo, Brazil; and Department of Rheumatology (Y.W.), Grove Hill Medical Center and The Hospital of Central Connecticut, New Britain, Connecticut.

Please address correspondence to Maksim Shapiro, MD, Departments of Radiology and Neurology, Bernard and Irene Schwartz Neurointerventional Radiology Section, NYU Langone Medical Center, 660 First Ave, 7th floor, New York, NY 10016;

e-mail: neuroangio@neuroangio.org

http://dx.doi.org/10.3174/ajnr.A4415
Occurrence of foreign body embolization has been previously described in the neurointerventional literature following thrombolysis, tumor embolization, and coiling. ${ }^{4-6}$ Development of subcutaneous foreign body granulomas after coated sheath radial artery access is well-documented in the cardiac literature. ${ }^{7-9}$ Foreign body pulmonary emboli producing angiocentric granulomas have also been observed. ${ }^{10}$ Another source is a histopathologic review by Mehta et al. ${ }^{11}$

\section{Case Series}

Patient 1 (Figs 1 and 2) underwent unremarkable coil-supported Pipeline embolization of an incidental right trigeminal aneurysm using dual-groin access; the Pipeline deployment axis consisted of 5F Shuttle (Cook, Bloomington, Indiana), 058 Navien (Covidien), and Marksman (Covidien) catheters. The patient felt persistently tired during the subsequent 8 weeks, followed by development of left-sided weakness and left homonymous quadrantanopsia. CT showed multifocal right-hemisphere edema. MR imaging demonstrated multiple subcentimeter lesions, predominantly within the subcortical white matter and at the gray-white junctions. Most lesions showed both magnetic susceptibility and enhancement. None had restricted diffusion, and all were surrounded by extensive vasogenic edema. Empiric 6-week antibiotic treatment was undertaken concurrently with a 2-month course of dexamethasone. All neurologic symptoms resolved in 4 weeks. Serial MR imaging showed near-resolution of the edema. All 

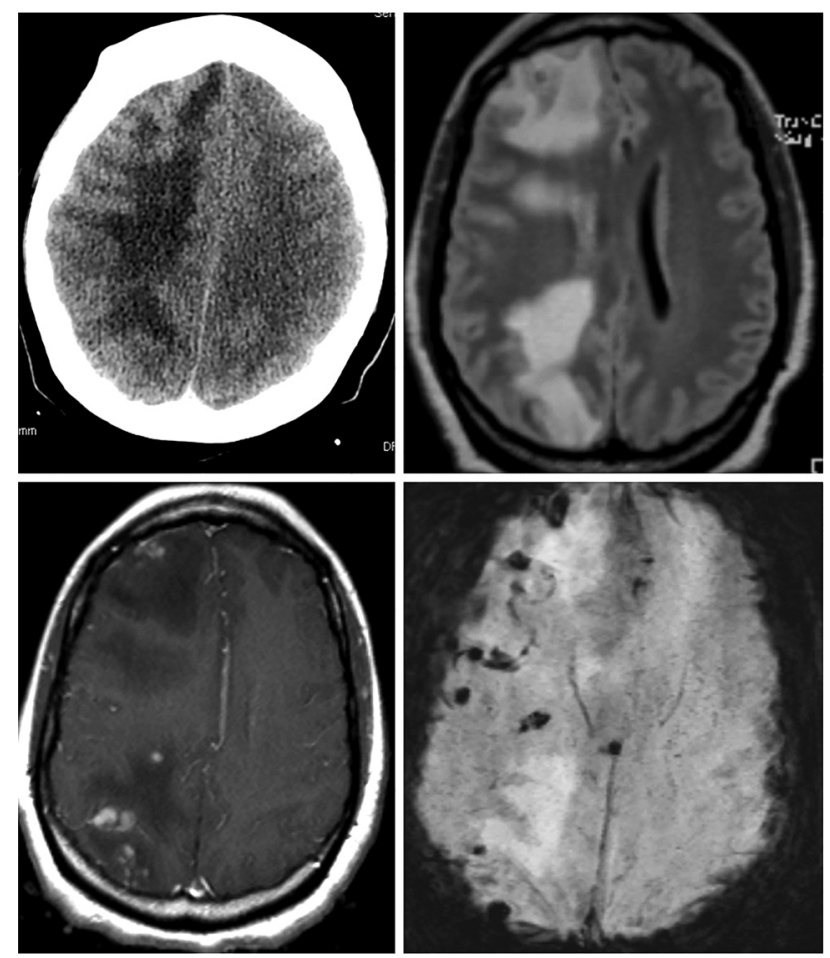

FIG 1. CT and MR images of patient 1.

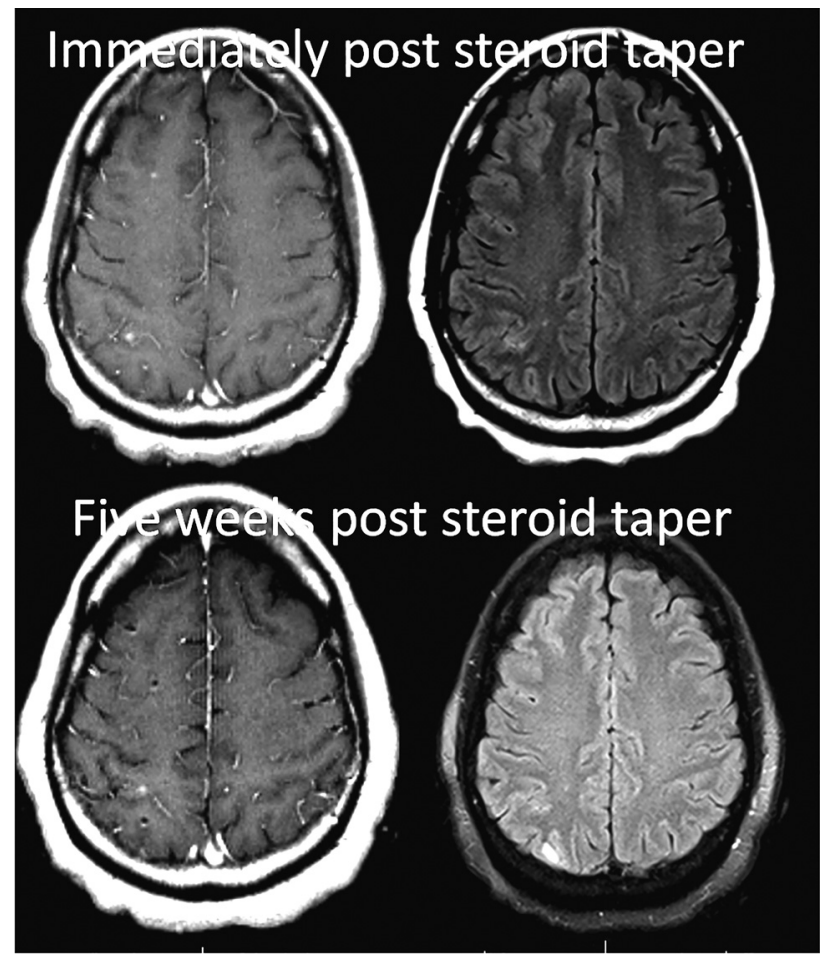

FIG 2. Patient 1, following a 2-month course of oral dexamethasone treatment.

lesions continue to enhance. Currently, the extent of magnetic susceptibility is unchanged, and no new lesions have developed.

Patient 2 (Fig 3) underwent uneventful coil-supported Pipeline embolization of a right paraophthalmic aneurysm, ${ }^{12}$ also using dual-groin access, with the Pipeline deployed through a triaxial system of 5F Arrow Sheath (Teleflex, Limerick, Pennsyl-
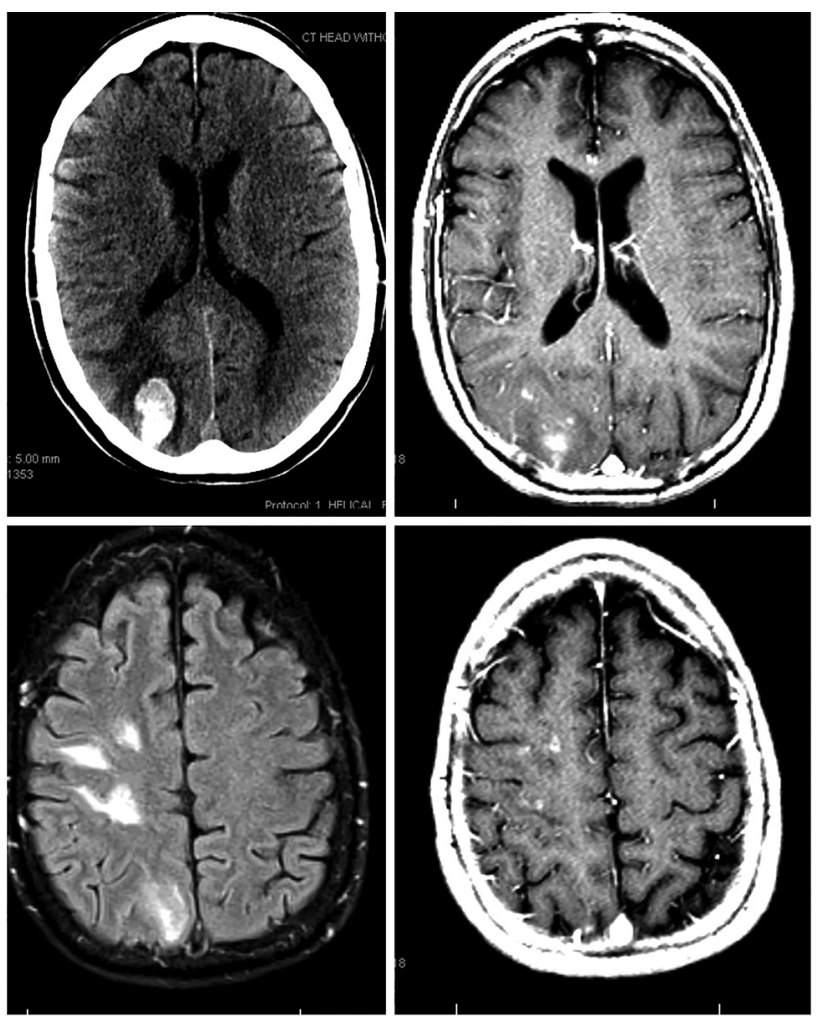

FIG 3. MR images of patient 2 on initial presentation.

vania), 5F Navien, and Marksman catheters. This patient also was tired during the next 2 months. On week 8 postembolization, she developed sudden headache and neck pain while watching a foreign movie and noticed difficulty reading the subtitles. Neurologic examination revealed left inferior homonymous quadrantanopsia. CT and MR imaging demonstrated a $2 \times 3 \mathrm{~cm}$ right parieto-occipital hematoma, with multiple subcortical enhancing lesions scattered throughout the ipsilateral hemisphere. The clopidogrel dosage was titrated to an empiric range of 100-200 P2Y12 reaction units (PRU). After an 8-week course of dexamethasone, MR imaging showed near-complete resolution of perilesional edema and decreased lesion enhancement, with no new lesions.

Patient 3 (Figs 4 and 5) presented with incidental bilateral paraophthalmic aneurysms, treated 4 weeks apart by coil-supported Pipeline embolization using single-groin access, with sequential deployment of coils and the Pipeline device, the latter through a triaxial system of 6F Shuttle, DAC 057 (Stryker, Kalamazoo, Michigan) and Marksman catheters. Persistent daily headaches developed 2 weeks later; MR imaging performed 2 months postembolization showed bilateral predominantly subcortical enhancing lesions, in this case with little edema and no susceptibility artifacts. Findings of extensive rheumatologic and infectious evaluations were negative. No treatment was undertaken. Two follow-up MRIs during 18 months showed an increase in the number and size of the lesions. A six-week course of corticosteroids had minimal effect on baseline mild edema or daily headaches. Biopsy of the left frontal lobe showed giant cell granulomas and reactive gliosis surrounding foreign body material with staining characteristics identical to those of a PVP coating. A 

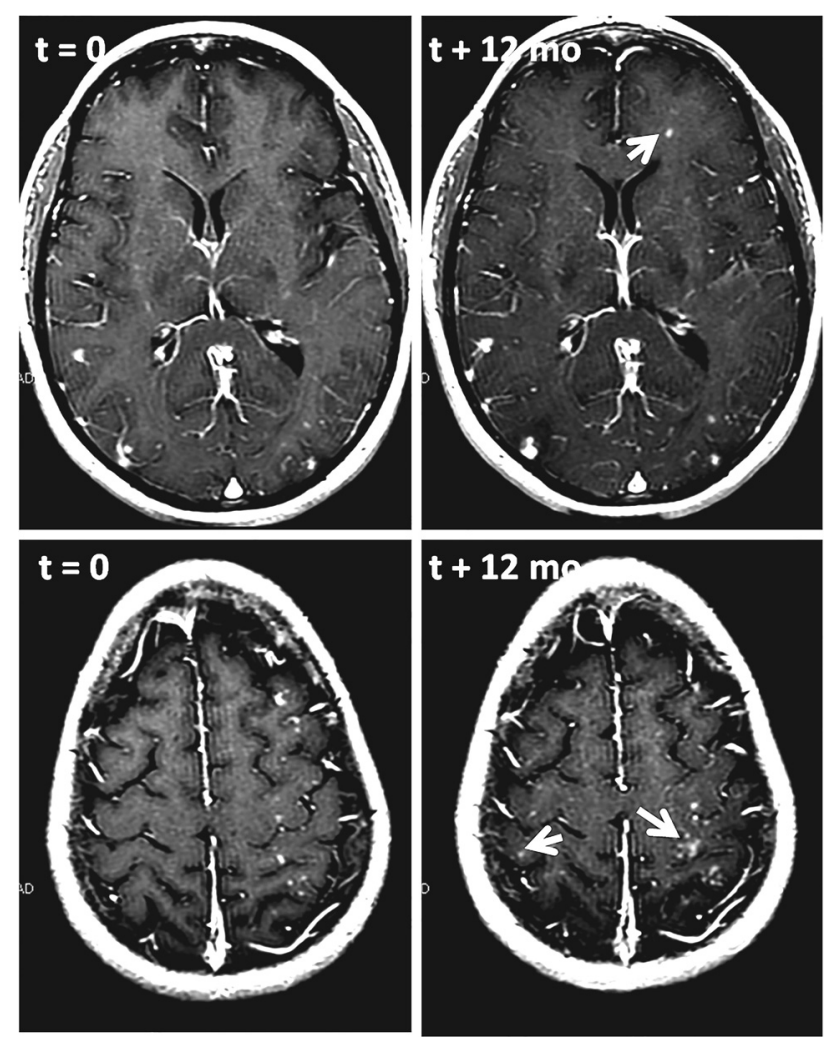

FIG 4. T7 postcontrast images of patient 3 , demonstrating an increase in the size and development of new enhancing lesions after 12 months of follow-up. Some new lesions are marked by arrows.
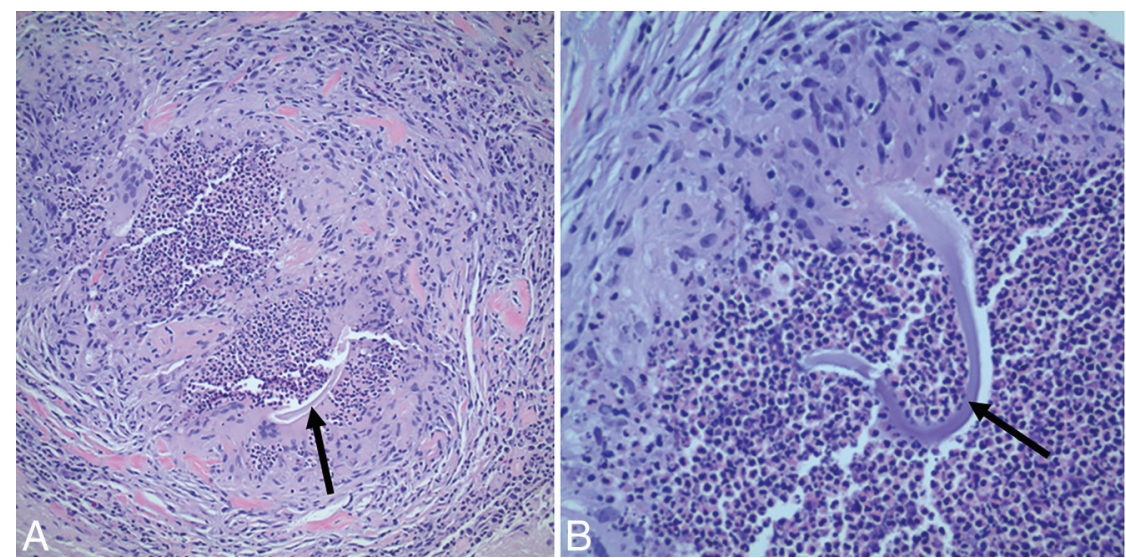

FIG 5. Patient 3. Right frontal lobe biopsy. Hematoxylin-eosin stain at $\times 200(A)$ and $\times 400(B)$ magnification demonstrates granulomatous angiitis with central blue-gray nonpolarizable foreign material, some with "cotton thread-like" appearance (arrows).

more delayed MR imaging 3 months post-steroid taper showed a decrease in the number and size of enhancing nodules. Surveillance is ongoing.

Patient 4 underwent Pipeline-supported coiling of an incidentally discovered right paraophthalmic aneurysm using singlegroin access, with Pipeline deployment through 6F Shuttle, 058 Navien, and Marksman catheters. She developed transient mild left hemiparesis 1 day postprocedure. MR imaging showed several diffusion-positive lesions. A catheter angiogram at this time showed complete patency of the Pipeline; however, at 6 months, the internal carotid artery was closed with asymptomatic com- plete hemisphere reconstitution via the anterior communicating artery. She developed periodic involuntary movements of the left upper extremity and left eyelid 3 months postembolization, increasing in duration and frequency; mild hemiparesis followed. CT and MR imaging showed right-hemisphere edema, with multiple subcortical enhancing lesions, many demonstrating susceptibility. Electroencephalography demonstrated focal slowing in the right parietal region with no epileptiform discharges. Right frontal biopsy showed granulomatous angiitis surrounding amorphous foreign material, identical in staining characteristics to the coating of the Shuttle guide catheter (Fig 6). Abnormal movements resolved after treatment with antiepileptics and dexamethasone. Follow-up MR imaging showed near-complete disappearance of enhancing nodules, with areas of persistent white matter T2 hyperintensity. Several weeks after completion of the taper, symptoms recurred and steroid treatment was reinstated; the patient is being considered for alternative immunomodulating regimens due to steroid-related side effects.

Patient 5 underwent Y-stent-assisted coiling of a left middle cerebral artery aneurysm with single-groin access consisting of $6 \mathrm{~F}$ Shuttle, Navien 070, Excelsior XT-27 (Stryker), and Echelon-10 (Covidien) catheters. Embolization was notable for intraprocedural occlusion of 2 superior division frontal branches, with no immediate clinical sequelae. Transient episodes of right upper extremity paresthesia and spasm developed 2 weeks postembolization. Conventional angiography demonstrated recanalization of the aforementioned frontal branches. MR imaging and MR spectroscopy showed multiple enhancing lesions throughout the left MCA territory, the largest involving areas subserved by initially occluded branches. A course of oral corticosteroids was administered. MR imaging 3 months after the event showed decreased perilesional edema and reduced enhancement.

\section{DISCUSSION}

This article reports 2 biopsy-proved and 3 suspected cases of foreign body emboli after endovascular interventions. An incidence of $\sim 0.6 \%$ is estimated on the basis of the total number of aneurysm embolizations $(\sim 720)$ performed at our 6 institutions during the 2-year period, during which 5 cases came to attention. Because asymptomatic patients are not routinely subjected to cross-sectional imaging, additional clinically silent cases may exist. The embolic material appears to be a PVP catheter coating. Presumably the same substance was found on postmortem examination of patients dying after Pipeline embolization from ipsilateral parenchymal hemorrhage, as reported by Hu et al. ${ }^{1}$ Thus, both clinical and histopathologic evidence suggest that PVP embolization may have a spectrum of presentations, with the conditions of survivors of the initial event evolving into a subacute granulomatous angiitis. Although most patients present with symptoms related to perilesional edema, the frequently observed intralesional susceptibility signal and subacute development of nonlethal hematoma 
in patient 2 attest to a continued hemorrhagic potential beyond the periprocedural window. In our case, the catheter coating was identified by histopathologic staining techniques, whereas $\mathrm{Hu}$ et $\mathrm{al}^{1}$ used mass spectroscopy for what is likely a more definitive analysis. PVP-coated catheters were used in all 5 cases; however, coating methods, including other substances in the coating, may vary among manufacturers.

Foreign body granulomatous reaction seen in our cohort adds to previously documented instances in the neurointerventional, cardiology, and peripheral interventional literature. ${ }^{8,10,11}$ Both clinical and radiographic courses were similar to those in the case series of Cruz et al. ${ }^{3}$ Our management relies on corticosteroid modulation of the inflammatory response and empiric titration of antiplatelets to balance the risks of hemorrhagic conversion and thromboembolism. Most patients report headache and/or malaise throughout the postoperative period. Focal symptoms typically appear after $\sim 2$ months, often reflecting the conse-

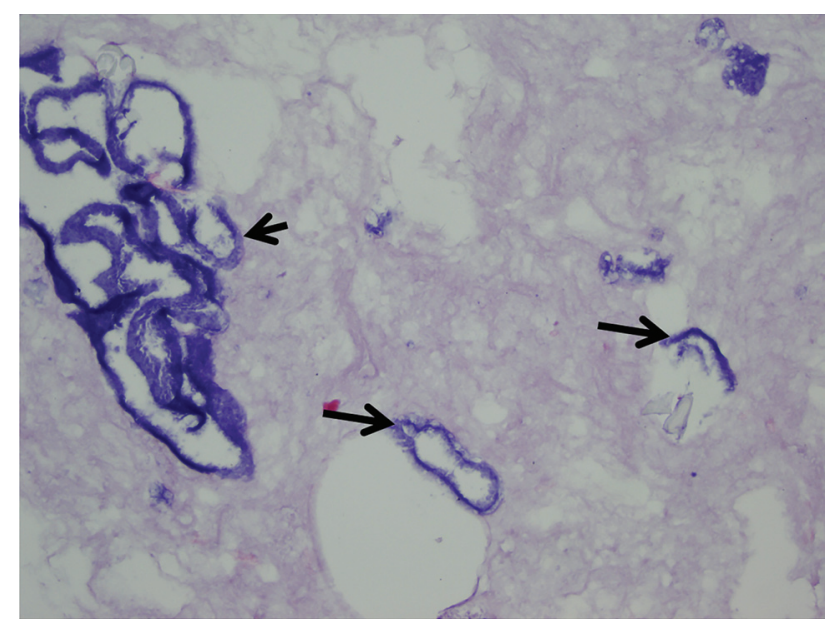

FIG 6. Hematoxylin-eosin stain of the outer coating (arrows) from the Flexor Shuttle guide catheter (Cook Medical, Bloomington, Indiana). quences of corticosteroid-responsive vasogenic edema. A radiographically heterogeneous course is notable-for example, the initial rise in the number and size of lesions followed by a decline in patients 3 and 4 versus a more static picture in patient 1 . Contributing factors may include the nature, extent, and effectiveness of individual immune reactions; phases of response to possible PVP breakdown products; and the role of corticosteroids.

Case 3 is unique in demonstrating bilateral lesions following 2 separate procedures performed 4 weeks apart. Coincidental bilateral embolization is possible. However, a cell-mediated allergictype reaction may be an intriguing alternative explanation, whereby only a subset of patients experiencing PVP embolization develop clinicopathologic manifestations based on individual reactions to the emboli. Allergies to food/medication/contrast material were reported in 4 of 5 patients (Table 1). The prevalence of allergy to any food in the US population is $10 \%-15 \%,{ }^{13,14}$ while medication allergies and adverse reactions are at 5\%-15\%. ${ }^{15}$ Thus, a 30\% estimate of combined food and medication allergy in the US population is substantially lower than the $80 \%$ seen in our cohort.

Allergic reactions to PVP have been reported. ${ }^{16-18}$ Aside from its use in catheter technology, PVP has many applications-for example, as a thickening and emulsifying agent in toothpastes, shampoos, contact lens solutions, and gel and tablet formulations. In combination with iodine, it forms the polyvinylpyrrolidone-iodine solution better known as Betadine (Betadine Microbicides, Stamford, Connecticut). Two instances of anaphylaxis to Betadine were traced to its PVP, rather than iodine, component. ${ }^{17,18}$ An anaphylactic reaction to an acetaminophen tablet was traced to its PVP ingredient. ${ }^{16}$ However, our cases would be more consistent with a type IV, cell-mediated response, rather than a type I, an anaphylactic one. Materials other than PVP are also present in the hydrophilic coating. Further investigation may be warranted.

From a technical standpoint, all our procedures were associated with the use of potentially tight-fitting catheter combinations

Table 1: Case details

\begin{tabular}{|c|c|c|c|c|c|}
\hline Parameter & Case 1 & Case 2 & Case 3 & Case 4 & Case 5 \\
\hline Allergy & lodinated contrast & Peanuts; sesame oil & Carisoprodol; NSAIDs & No known allergies & lodinated contrast \\
\hline $\begin{array}{l}\text { Length of clinical follow-up to } \\
\text { date (mo) }\end{array}$ & 15 & 13 & 33 & 4.5 & 3.5 \\
\hline $\operatorname{ESR}(\mathrm{mm} / \mathrm{h})$ & 56 & 12 & 8 & 11 & 46, then 21 \\
\hline CRP (mg/dL) & $<5$ & $<7$ & $<0.2$ & 0.25 & 1.3 then 3.7 \\
\hline $\begin{array}{l}\text { Periprocedural antiplatelet } \\
\text { monitoring }\end{array}$ & $\mathrm{PRU}=97$ & $\mathrm{PRU}=96$ & $\mathrm{PRU}=38$ & $P R U=120$ & $A D P=35 \%$ \\
\hline $\begin{array}{l}\text { Antiplatelet monitoring at } \\
\text { readmission }\end{array}$ & $\mathrm{PRU}=101$ & $\mathrm{PRU}=2$ & Not done & $\mathrm{PRU}=215$ & Not done \\
\hline $\mathrm{WBC}(\mathrm{K} / \mu \mathrm{L})$ & 7 & 11.4 & 8.8 & 11.6 & 9.7 \\
\hline Platelets $(\mathrm{K} / \mu \mathrm{L})$ & 297 & 345 & 254 & 184 & 314 \\
\hline Blood culture & Negative & Negative & Negative & Negative & Not done \\
\hline CSF appearance & Clear, colorless & Clear, colorless & Clear, colorless & Clear, pale yellow & Clear, colorless \\
\hline CSF opening pressure $\left(\mathrm{cm} \mathrm{H}_{2} \mathrm{O}\right)$ & 17 & 15 & NA & NA & 20 \\
\hline CSF RBC (No./HPF) & 0 & 6 & 0 & 273 & 3 \\
\hline CSF WBC (No./HPF) & 4 & 1 & 1 & 2 & 25 \\
\hline CSF \% lymphocytes & $90 \%$ & NA & $62 \%$ & $80 \%$ & $78 \%$ \\
\hline CSF protein (mg/dL) & 96 & 71 & 35 & 92 & 66 \\
\hline CSF Gram stain & Negative & Negative & Negative & Negative & Negative \\
\hline CSF culture & Negative & Negative & Negative & Negative & Negative \\
\hline
\end{tabular}

Note:-ESR indicates erythrocyte sedimentation rate; CRP, C-reactive protein; WBC, white blood cell count; RBC, red blood cell count; HPF, high-power field.; NSAID, nonsteroidal anti-inflammatory drug; ADP, adenosine diphosphate; NA, not applicable. 


\begin{tabular}{|c|c|c|c|c|c|}
\hline Tools & Case 1 & Case 2 & Case 3 & Case 4 & Case 5 \\
\hline Diagnostic catheter & $5 F$ VER ${ }^{a}$ & $5 F$ VER ${ }^{a}$ & 4F Glidecath ${ }^{b}$ & 4F Glidecath ${ }^{\mathrm{b}}$ & $5 F$ VER ${ }^{a}$ \\
\hline Diagnostic wire & $038^{\mathrm{b}}$ & $038^{\mathrm{b}}$ & $038^{\mathrm{b}}$ & $038^{\mathrm{b}}$ & $J \& 035^{c}$ \\
\hline Exchange wire & Wholey Exchange ${ }^{d}$ & Wholey Exchange ${ }^{d}$ & Amplatz SuperStiffe & Amplatz SuperStiffe & Amplatz SuperStiffe \\
\hline Sheath & Shuttle $5 F$ & Arrow $5 \mathrm{~F}$ & Shuttle $6 \mathrm{~F} \times 2$ & Shuttle 6F & Shuttle 6F \\
\hline Second catheter & Envoy $5 F^{f}$ & Envoy $5 F^{f}$ & None & None & None \\
\hline Distal support catheter & Navien 058 & Navien 058 & Neuron-053, ${ }^{g}$ DAC-057 & Navien 058 & Neuron $070^{g}$ \\
\hline Microcatheter & Marksman-150 & Marksman-150 & Marksman-150 × 2 & Marksman-150 & Excelsior XT-27 \\
\hline Microcatheter, other & Echelon-10 & Excelsior SL-10 ${ }^{\mathrm{j}}$ & $\begin{array}{l}\text { Echelon 10, PX-400, }{ }^{\mathrm{h}} \text { Prowler } \\
\text { Select Plus }\end{array}$ & PX-Slim & Echelon-10 \\
\hline Microwire & $\begin{array}{l}\text { Transend } 014^{j} \\
\text { Platinum }^{i}\end{array}$ & $\begin{array}{l}\text { Transend } 014^{j} \\
\text { Platinum }\end{array}$ & Fathom-16, ${ }^{e}$ X-Celerator-14 & $\begin{array}{l}\text { Synchro2 Std, }{ }^{\mathrm{e}} \\
\text { X-Celerator-14 }^{\mathrm{d}}\end{array}$ & SilverSpeed-14 ${ }^{\mathrm{d}}$ \\
\hline Devices & Pipeline $4.5 \times 14$ & Pipeline $3.75 \times 12$ & $\begin{array}{l}\text { Pipeline } 3.5 \times 20,3.5 \times \\
\quad 18,4.0 \times 20\end{array}$ & Pipeline $4.0 \times 18$ & $\begin{array}{l}\text { Neuroform EZ,' LEO } \\
\text { Baby }^{k}\end{array}$ \\
\hline Coils & Target $^{\mathrm{j}}$ & Target $^{\mathrm{j}}$ & Cosmos, 'Penumbra $400^{\circ}$ & Penumbra $400^{\circ}$ & Axium $^{d}$ \\
\hline Other & & & $\begin{array}{l}\text { Alligator, }{ }^{m} \text { Amplatz goose } \\
\text { neck snare }\end{array}$ & ScepterC $4 \times 15 \mathrm{~mm}^{\prime}$ & \\
\hline
\end{tabular}

${ }^{a}$ Cordis, Miami Lakes, Florida.

b Terumo, Tokyo, Japan.

${ }^{c}$ Cordis, Fremont, California.

${ }^{\mathrm{d}}$ Covidien.

e Boston Scientific, Natick, Massachusetts.

${ }^{f}$ Codman \& Shurtleff, Raynham, Massachusetts.

8 Penumbra, Alameda, California

${ }^{\mathrm{h}}$ biyodenge, Ankara, Turkey.

'Eagle Eye Platinum; Volcano Corporation, Rancho Cordova, California.

i Stryker Neurovascular, Kalamazoo, Michigan.

k Balt Extrusion, Montmorency, France.

'MicroVention, Tustin, California.

${ }^{\mathrm{m}}$ Chestnut Medical Technologies, Menlo Park, California.

(Table 2). PVP embolization could be related to intercatheter friction, made increasingly common by the adoption of triaxial configurations for deployment of present day devices. We modified our protocols to avoid marginally accommodated access components and favor 2-groin access for coil-supported Pipeline embolization. No new case has yet emerged after these changes. Our series does not suggest that the Pipeline device is the source of emboli, nor is the Shuttle guide catheter the sole culprit as highlighted by case 2, in which an Arrow guide catheter was used. In another instance, we have aspirated coating from a 4.3 DAC catheter used in combination with a Marksman microcatheter, another very tight coupling we have abandoned. Notably, this patient did not develop evidence of foreign body emboli, lending further support to the allergic mechanism hypothesis.

Although the numeric incidence of symptomatic cathetercoating embolization appears to be low, it is disturbing to see that having been identified as a concern in the cerebrovascular and other fields $>15$ years ago, the issue seems to be on the rise rather than declining, creating lethal and long-term nonlethal damage. We hope that highlighting such cases will result in prompt attention from catheter and coating manufacturers so that this chapter in the book of neurointerventional complications may finally be completed.

\section{CONCLUSIONS}

Catheter-coating embolization is well-documented in peripheral, cardiology, and neurointerventional literature. While some patients with CNS emboli develop catastrophic hemorrhage shortly after the procedure, ${ }^{1}$ this and other series ${ }^{3}$ confirm that foreign body emboli elicit a spectrum of manifestations. Survivors of the initial insult may develop a granulomatous angiitis characterized by enhancement, perilesional edema, and local microhemorrhage. The PVP coating appears to be responsible for the current generation of cases. We propose the possibility of an allergic-type response, with emboli possibly remaining asymptomatic in some or most cases or reactions developing after the breakdown of PVP into more biologically active components. From the technical standpoint, embolization may be related to the use of sophisticated catheter-support systems, increasing the possibility of intercatheter friction. Symptoms may be successfully managed with corticosteroids and antiplatelet monitoring. One should consider the following recommendations:

- Avoid tight-fitting catheter-intermediate catheter-microcatheter combinations; consider 2-groin access for multicatheter scenarios, especially those involving larger sized microcatheters required for the delivery of many currently implanted devices.

- Focal symptoms emerging several months after embolization in a background of nonspecific symptoms, such as headache and malaise, are typical, especially in patients with food or drug allergies.

- An MR imaging pattern of multiple enhancing lesions with surrounding edema and susceptibility, in the vascular territory of an index lesion, is highly characteristic.

- A corticosteroid regimen of 4- to 8-week duration is typically effective in controlling perilesional edema, which is often responsible for focal symptoms. A decrease in the size and/or number of enhancing lesions may not be evident for several weeks after completion of the taper. This should be taken into account when assessing the effectiveness and contemplating alternative regimens. 
- Adjustment of the antiplatelet regimen to avoid overinhibition may be beneficial.

Disclosures: Maksim Shapiro_UNRELATED: Consultancy: Covidien, Comments: I am a proctor and consultant with Covidien, manufacturer of the Pipeline device; Grants/Grants Pending: I have a grant, for Pipeline devices only, from Covidien, manufacturer of the Pipeline device. The purpose of the grant is to study the properties of the Pipeline device; Payment for Development of Educational Presentations: I am a proctor and consultant with Covidien, manufacturer of the Pipeline device. Tibor Becske-UNRELATED: Consultancy: Covidien, Comments: proctoring and consulting; Payment for Lectures (including service on Speakers Bureaus): Covidien; Payment for Development of Educational Presentations: none in the past 36 months. Daniel Zumofen-UNRELATED: Grants/Grants Pending: Helmut Hartweg Fund, Swiss Academy of Medical Science, Comments: personal scholarship not related to the submitted publication. Peter K. Nelson-UNRELATED: Consultancy: Covidien, Comments: consultant and Pipeline proctor.

\section{REFERENCES}

1. Hu YC, Deshmukh VR, Albuquerque FC, et al. Histopathological assessment of fatal ipsilateral intraparenchymal hemorrhages after the treatment of supraclinoid aneurysms with the Pipeline Embolization Device. J Neurosurg 2014;120:365-74 CrossRef Medline

2. Francois P, Vaudaux P, Nurdin N, et al. Physical and biological effects of a surface coating procedure on polyurethane catheters. Biomaterials 1996;17:667-78 CrossRef Medline

3. Cruz JP, Marotta T, O'Kelly C, et al. Enhancing brain lesions after endovascular treatment of aneurysms. AJNR Am J Neuroradiol 2014;35:1954-58 CrossRef Medline

4. Barnwell SL, D'Agostino AN, Shapiro SL, et al. Foreign bodies in small arteries after use of an infusion microcatheter. AJNR Am J Neuroradiol 1997;18:1886-89 Medline

5. Fealey ME, Edwards WD, Giannini C, et al. Complications of endovascular polymers associated with vascular introducer sheaths and metallic coils in 3 patients, with literature review. Am J Surg Pathol 2008;32:1310-16 CrossRef Medline

6. Mehta RI, Mehta RI, Fishbein MC, et al. Intravascular polymer material after coil embolization of a giant cerebral aneurysm. Hum Pathol 2009;40:1803-07 CrossRef Medline
7. Kozak M, Adams DR, Ioffreda MD, et al. Sterile inflammation associated with transradial catheterization and hydrophilic sheaths. Catheter Cardiovasc Interv 2003;59:207-13 CrossRef Medline

8. Sado D, Witherow F. Sterile granuloma formation following radial artery facilitated coronary catheterization. Catheter Cardiovasc Interv 2009;74:606 CrossRef Medline

9. Saririan M, Pyne CT. Sterile granuloma formation following radial artery catheterization: too many cooks? Catheter Cardiovasc Interv 2010;76:907-08; author reply 909-10 CrossRef Medline

10. Allan RW, Alnuaimat H, Edwards WD, et al. Embolization of hydrophilic catheter coating to the lungs: report of a case mimicking granulomatous vasculitis. Am J Clin Pathol 2009;132:794-97 CrossRef Medline

11. Mehta RI, Mehta RI, Solis OE, et al. Hydrophilic polymer emboli: an under-recognized iatrogenic cause of ischemia and infarct. Mod Pathol 2010;23:921-30 CrossRef Medline

12. Shapiro M, Becske T, Riina HA, et al. Toward an endovascular internal carotid artery classification system. AJNR Am J Neuroradiol 2014;35:230-36 CrossRef Medline

13. McGowan EC, Keet CA. Prevalence of self-reported food allergy in the National Health and Nutrition Examination Survey (NHANES) 2007-2010. J Allergy Clin Immunol 2013;132:1216-19.e5 CrossRef Medline

14. Vierk KA, Koehler KM, Fein SB, et al. Prevalence of self-reported food allergy in American adults and use of food labels. J Allergy Clin Immunol 2007;119:1504-10 CrossRef Medline

15. Thong BY, Tan TC. Epidemiology and risk factors for drug allergy. Br J Clin Pharmacol 2011;71:684-700 CrossRef Medline

16. Rönnau AC, Wulferink M, Gleichmann E, et al. Anaphylaxis to polyvinylpyrrolidone in an analgesic preparation. Br J Dermatol 2000; 143:1055-58 CrossRef Medline

17. Yoshida K, Sakurai Y, Kawahara S, et al. Anaphylaxis to polyvinylpyrrolidone in povidone-iodine for impetigo contagiosum in a boy with atopic dermatitis. Int Arch Allergy Immunol 2008;146: 169-73 CrossRef Medline

18. Adachi A, Fukunaga A, Hayashi K, et al. Anaphylaxis to polyvinylpyrrolidone after vaginal application of povidone-iodine. Contact Dermatitis 2003;48:133-36 CrossRef Medline 